\title{
Multistate foodborne hepatitis A outbreak among European tourists returning from Egypt- need for reinforced vaccination recommendations, November 2012 to April 2013
}

J Sane (jusa83@gmail.com) 1,2, E MacDonald 2,3, L Vold³, C Gossner ${ }^{4,5}$, E Severi, on behalf of the International Outbreak Investigation Team ${ }^{6}$

1. National Institute for Public Health and the Environment (RIVM), Centre for Infectious Disease Control, Bilthoven, the Netherlands

2. European Programme for Intervention Epidemiology Training (EPIET), European Centre for Disease Prevention and Control $(E C D C)$, Stockholm, Sweden

3. Norwegian Institute of Public Health, Oslo, Norway

4. European Centre for Disease Prevention and Control (ECDC), Stockholm, Sweden

5. School of Public Health and Primary Care (CAPHRI), Maastricht University Medical Centre (MUMC+), Maastricht, The Netherlands

6. Members of the team are listed at the end of the article

Citation style for this article:

Sane J, MacDonald E, Vold L, Gossner C, Severi E, on behalf of the International Outbreak Investigation Team. Multistate foodborne hepatitis A outbreak among European tourists returning from Egypt- need for reinforced vaccination recommendations, November 2012 to April 2013. Euro Surveill. 2015;20(4):pii=21018. Available online: http://www.eurosurveillance.org/ViewArticle.aspx?Articleld=21018

Article submitted on 07 February 2014 / published on 29 January 2015

A multistate outbreak of hepatitis A virus (HAV) among European travellers returning from Egypt occurred between November 2012 and April 2013. A total of 14 European Union (EU)-European Free Trade Association (EFTA) countries reported 107 cases. Twenty-one cases from six countries were affected by strains of subgenotype IB harbouring identical RNA sequences, suggesting a common source outbreak. An international outbreak investigation team interviewed a number of cases with a trawling questionnaire to generate hypotheses on potential exposures. Some of these exposures were further tested in a case-control study based on a more specific questionnaire. Both trawling and case-control questionnaires aimed to collect cases' vaccination details as well as epidemiological information. Most cases participating in either questionnaire (35/43) had been staying in all-inclusive hotels located along the Red Sea. The case-control study found cases associated with exposure to strawberries or mango (multivariable analysis $p$ value: 0.04). None of the 43 cases interviewed in any of the two questionnaires had been vaccinated. The most common reasons for non-vaccination was unawareness that HAV vaccination was recommended (23/43, $53 \%$ ) and perceiving low infection risk in all-inclusive luxury resorts (19/43, 44\%). Vaccination had not been recommended to five of the six cases who sought travel medical advice before travelling. Public health authorities should strongly reinforce measures to remind travellers, travel agencies and healthcare providers of the importance of vaccination before visiting HAV-endemic areas, including Egypt.

\section{Introduction}

Hepatitis $A$ is an acute illness caused by hepatitis $A$ virus (HAV), which is characterised by dark urine, discoloured faeces, fatigue, fever and jaundice. Transmission mainly occurs through ingestion of contaminated food and water, and via the faecal-oral route among close contacts to infected persons. The incubation period for hepatitis $A$ is approximatively 30 days and can range from 15 to 50 days [1]. The risk of developing symptomatic illness following HAV infection is related to age: in young children ( $\leq 5$ years of age), HAV infection is usually asymptomatic but among older children and adults, infection usually causes clinical disease with jaundice occurring in more than $70 \%$ of cases [2].

The incidence of HAV infection has been declining in most countries of the European Union (EU) during recent decades, reflecting improved hygiene and living conditions, and was estimated at 2.5 per 100,000 in European Economic Area-EU countries in 2011 [3]. However, hepatitis $A$ remains one of the most common travel-related diseases among European travellers $[4,5]$. An effective and safe vaccine against HAV infection is available on the market since the early $1990 \mathrm{~s}$ $[2,6]$.

On 15 April 2013, the Norwegian Institute of Public Health communicated through the Epidemic Intelligence Information System for Food-and Waterborne Diseases and Zoonoses platform (EPIS-FWD) of the European Centre for Disease Prevention and Control (ECDC) an increase in HAV infections in travellers returning from Egypt compared with the normal annual rate [7]. 
Following Norway's notification, several EU-European Free Trade Association (EFTA) countries reported cases with disease onset after 1 November 2012 and recent travel history to Egypt (mainly to resorts in the Red Sea). Some of these cases shared identical viral RNA sequences (genotype IB) to the outbreak strain isolated in four Norwegian patients. Egypt, and particularly the Red Sea area, is a popular tourist destination for European travellers [7]; HAV infection in Egypt remains highly endemic and the virus is frequently detected in the environment [8].

The significant increase of travel-related cases compared with the historical baseline at country level, together with the identification of the same HAV sequence in cases from different countries, suggested a multistate outbreak [9]. An outbreak investigation coordinated by the ECDC and involving several public health institutes in EU-EFTA, the World Health Organization (WHO) Regional Offices (RO) for Europe and the Eastern Mediterranean as well as Egyptian public health authorities, was initiated to identify common exposures among cases. Moreover, to determine if vaccination recommendations to travellers should be reinforced, the vaccination details of cases were sought. While the first cases and outbreak strain sequence were described in a preliminary report, which was published when the epidemic was ongoing [7] more detailed findings of the epidemiological investigation are presented here, including the results of a case-control study.

\section{Methods}

\section{Case definition and case finding}

After the initial alert in EPIS-FWD, the following EU-EFTA epidemic case definition was established: A probable case was defined as a symptomatic person with a laboratory-confirmed HAV infection (presence of IgM and/or polymerase chain reaction (PCR)-positive), with onset of symptoms (or date of testing if onset date not available) after 1 November 2012, with travel history to Egypt two to six weeks before onset of symptoms (or date of testing if onset date not available) and no other known hepatitis A exposure. A confirmed case was defined as a probable case with HAV RNA sequence matching the outbreak sequence first isolated from Norwegian cases [7]. Cases, for which typing was performed but resulted in a sequence different to the outbreak strain, were excluded. Countries were asked to report to ECDC via the EPIS-FWD platform the number of HAV cases meeting the outbreak case definition together with available information on demographic characteristics, clinical features and travel details.

\section{Trawling questionnaire}

The International Outbreak Investigation Team (IOT) developed a trawling questionnaire in order to generate hypotheses on potential risk exposures. The primary aim was to interview confirmed cases clustered in the same hotels, but countries were encouraged to interview also probable cases from these hotels when this was not possible. Trawling questionnaire collected information on basic demographics, symptoms, vaccination status, travel details (travel agencies, airports, airlines), holiday activities (swimming, scuba diving, snorkelling, day/night trips) and food and drink consumption at the hotel food services during the stay in Egypt. Questionnaires were translated to respective languages, and staff from the cases' respective national public health authorities conducted the trawling interviews.

\section{Case-control study}

We designed a case-control study in order to identify risk factors associated with disease transmission by testing hypotheses on exposures found through the trawling questionnaire. Both confirmed and probable cases staying at the same hotels during the same time period (between January and March 2013) as at least one confirmed case were eligible for inclusion in the case-control study.

Cases eligible for the case-control study were asked to nominate as controls travel companions staying at the same hotel during the same period, a form of convenience sampling. Controls were excluded if they reported history of HAV vaccination or had knowingly been infected with HAV (to exclude as many controls who would have been protected against infection as possible) or were under 16 years of age (to minimise misclassification due to asymptomatic infection).

The IOT developed the case-control questionnaire (available on request), which included the same questions on basic demographics, symptoms and vaccination details as the trawling questionnaire; however, it comprised more detailed questions on consumption of food and drink items most frequently mentioned in the answers to the trawling questionnaire. Cases recruited for the case-control study, which had not been previously investigated with the trawling questionnaire, were interviewed with the case-control questionnaire. For cases considered in the case-control study which had already participated in the trawling questionnaire, we developed a supplementary questionnaire including only the detailed questions on exposures of interest. Cases either completing the case-control questionnaire, or the trawling questionnaire followed by the supplementary questionnaire, were included in the case-control study.

Assessment of vaccination details among cases As all countries affected by the outbreak had explicit HAV vaccination recommendations for travellers to Egypt, we aimed to study the vaccination status and reasons for non-vaccination among cases in order to find out if awareness of these recommendations should be improved. Both the trawling and case-control questionnaire collected information on vaccination (vaccination status, year of vaccination and dose, allowing calculation whether vaccination was protective at time 
of travel). Participants were also asked whether advice was sought from medical professionals before their trip to Egypt and if yes, whether vaccination was recommended, not recommended or not discussed during the consultation. Furthermore, the cases were asked to specify reasons for non-vaccination. All cases interviewed in the trawling questionnaire or in the casecontrol study were included in the descriptive analyses on vaccination.

\section{Data analysis}

We describe cases and controls in terms of demographics (age, sex and country of origin), clinical symptoms (cases) and exposures of interest through crude numbers and proportions. Food items served in different forms (e.g. strawberries as fresh fruit, in smoothies, pastries or in fruit sauce) were recoded into a single exposure variable. In the univariate analysis, we assessed the associations between outcome and exposures of interest by calculating odds ratios (OR) and $95 \%$ confidence intervals $(\mathrm{Cl})$, and determined the p-value with the Fisher exact test. To adjust for potential confounders, we fitted into a multivariable logistic regression model any exposure positively associated with the outcome with a $p$-value $<0.25$, excluding those with fewer than 10 cases [10]. We used STATA version 12 (Statacorp, College Station, Texas) to perform the analysis.

\section{FIGURE 1}

Weekly distribution of probable and confirmed hepatitis A infection cases with travel history to Egypt, European Union-European Free Trade Association, November 2012April $2013(\mathrm{n}=102)^{\mathrm{a}}$

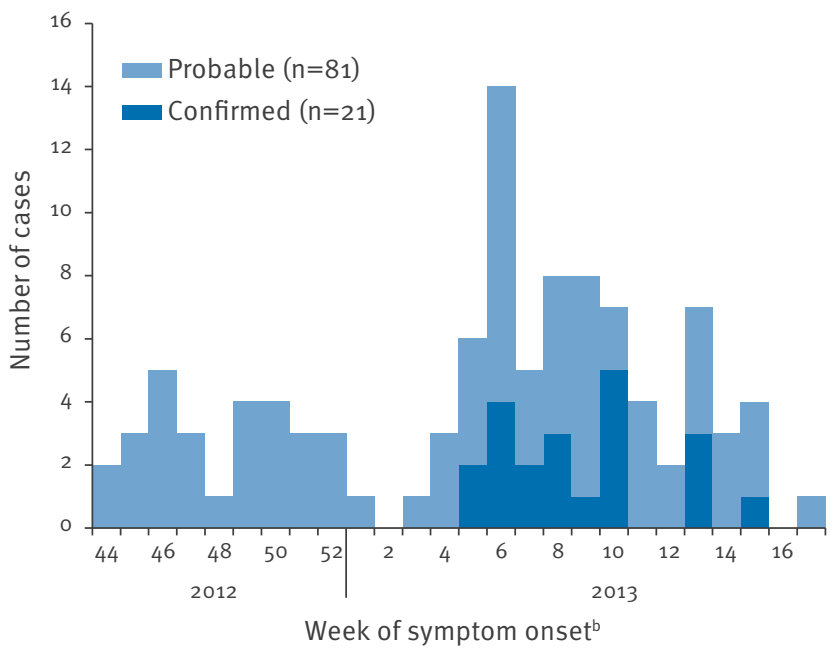

Five probable cases are not included in the figure due to missing information on onset date and testing date. Cases were reported from following countries: Denmark $(n=8)$, Estonia $(n=1)$, Finland $(n=2)$, France $(n=9)$, Germany $(n=44)$, Ireland $(n=2)$, Latvia $(n=1)$, Lithuania $(n=3)$, the Netherlands $(n=10)$, Norway $(n=7)$, Slovakia $(n=2)$, Sweden $(n=6)$, Switzerland $(n=3)$, United Kingdom $(n=9)$.

b Date of testing for hepatitis A virus was used if symptom onset date was not available ( $n=13$ cases).
Numbers of cases recruited to participate in the trawling questionnaire and number of cases and controls for the case-control study, European travellers to Egypt, 2012-2013
Cases fulfilling the outbreak case definition

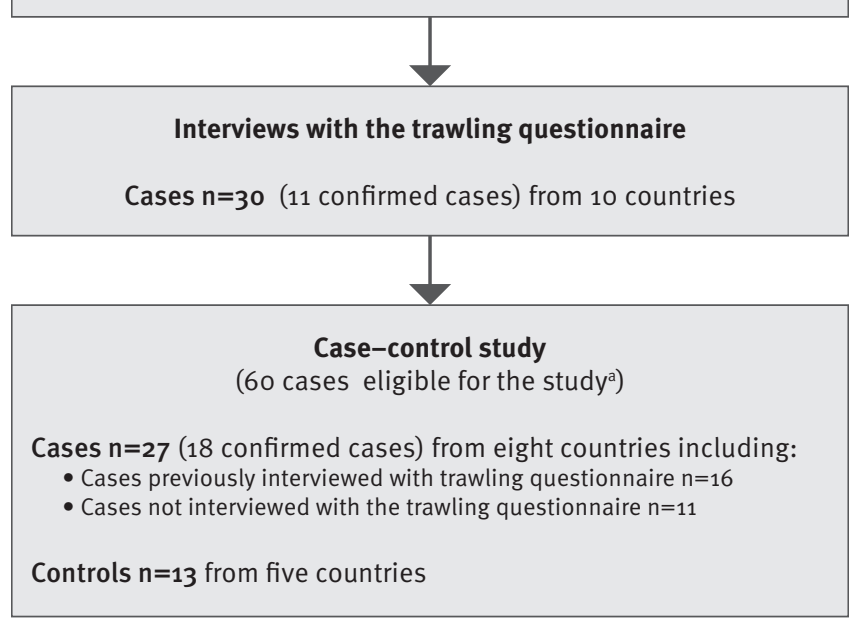

Both confirmed and probable cases staying at the same hotels during the same time period (January-March 2013) as at least one confirmed case were eligible for inclusion in the case control study.
Cases $n=107$ ( 21 confirmed cases) from 14 countries

\section{Laboratory methods}

Laboratory confirmation of HAV infection included a positive IgM and/or PCR result, which was determined by standard serological or virological methods in the respective countries. If feasible, the RNA sequence of $\mathrm{HAV}$ (442 nucleotides in $\mathrm{VP}_{1} / 2 \mathrm{~A}$ region) was determined in laboratories in different countries following respective protocols. The outbreak strain sequence has been published previously [7].

\section{Results}

Description of the outbreak

A total of 107 cases ( 21 confirmed and 86 probable) were reported from the following EU-EFTA countries: Denmark $(n=8)$, Estonia $(n=1)$, Finland $(n=2)$, France $(n=9)$, Germany $(n=44)$, Ireland $(n=2)$, Latvia $(n=1)$, Lithuania $(n=3)$, the Netherlands $(n=10)$, Norway $(n=7)$, Slovakia $(n=2)$, Sweden $(n=6)$, Switzerland $(n=3)$ and the United Kingdom (UK) $(n=9)$. For the 102 cases with available information, the date of symptom onset, or date of testing (if onset date was not available), ranged from 2 November 2012 (week 44) to 26 April 2013 (week 17) (Figure 1). Most cases $(n=72,71 \%)$ occurred between January and April (weeks 3 to 15) 2013 with a peak in case numbers in week six (February). Six countries (Denmark, France, Ireland, the Netherlands, Norway, and the UK) identified confirmed cases $(n=21)$; all were reported in 2013 (Figure 1). Confirmed cases 
Demographic characteristics and clinical symptoms (if applicable) of hepatitis A cases and controls, European travellers to Egypt, November 2012-April 2013

\begin{tabular}{|c|c|c|c|}
\hline Characteristics & $\begin{array}{l}\text { All reported cases } \\
\quad(n=107)\end{array}$ & $\begin{array}{l}\text { Cases in case-control study } \\
\qquad(n=27)^{\mathrm{a}}\end{array}$ & $\begin{array}{l}\text { Controls in case-control study } \\
\qquad(\mathrm{n}=13)\end{array}$ \\
\hline Female $\mathrm{n} / \mathrm{N}^{\mathrm{b}}(\%)$ & $50 / 101(50)$ & $16 / 27(59)$ & $6 / 13(46)$ \\
\hline Median age in years (range) & $36(4-76)$ & $39(5-72)$ & $48(27-70)$ \\
\hline Confirmed case $\mathrm{n} / \mathrm{N}^{\mathrm{b}}(\%)$ & $21 / 107(20)$ & $14 / 27(52)$ & NA \\
\hline Median length of stay in Egypt in days (range) & $7(1-80)$ & $7(6-14)$ & $7(6-14)$ \\
\hline \multicolumn{4}{|l|}{ Symptoms } \\
\hline Dark urine or coloured stools $\mathrm{n} / \mathrm{N}^{\mathrm{b}}(\%)$ & - & $27 / 27(100)$ & NA \\
\hline Jaundice or yellow eyes $\mathrm{n} / \mathrm{N}^{\mathrm{b}}(\%)$ & - & $27 / 27(100)$ & NA \\
\hline Abdominal pain $\mathrm{n} / \mathrm{N}^{\mathrm{b}}(\%)$ & - & $19 / 27(70)$ & NA \\
\hline Vomiting $\mathrm{n} / \mathrm{N}^{\mathrm{b}}(\%)$ & - & $13 / 27(48)$ & NA \\
\hline Fever>38 $8^{\circ} \mathrm{C} n / \mathrm{N}^{\mathrm{b}}(\%)$ & - & $17 / 24(71)$ & NA \\
\hline Diarrhoea n/N $(\%)$ & - & $13 / 26(50)$ & NA \\
\hline Median duration of illness in days (range) & - & $21(4-60)$ & NA \\
\hline Hospitalised $\mathrm{n} / \mathrm{N}^{\mathrm{b}}(\%)$ & - & $18 / 27(67)$ & NA \\
\hline
\end{tabular}

NA: not applicable; -: not available.

a Includes 16 cases which had also been interviewed with trawling questionnaire.

b Total cases with respective available information.

reported staying in seven different hotels in three different geographically dispersed locations in Egypt; Taba, Sharm El Sheikh and Hurghada.

\section{Trawling questionnaire}

A flowchart summarising the number of cases recruited for the trawling questionnaire and the case-control study is shown in Figure 2.

Thirty cases were interviewed with the trawling questionnaire in May 2013, including 11 confirmed and 19 probable (Figure 2). Travel details and activities during the holiday did not suggest common activities and exposures among cases which stayed at different hotels in Egypt and came from different countries. Consumption of several food items at the hotel services was frequently mentioned by cases such as fresh fruits and berries, raw vegetables, different salads and orange juice. These exposures were included in the case-control study questionnaire.

\section{Case-control study}

Twenty-seven of the 60 cases eligible for the study were interviewed with the questionnaire between June and August 2013. Thirteen controls were included in the study (Figure 2). Cases and controls stayed at six and four different hotels, respectively. Participants' characteristics are presented in Table 1.

At univariate level, cases were more likely than controls to have consumed strawberries, raspberries and mango in any form ( $p$ value $\leq 0.05$, Table 2 ) with strawberry exposure mentioned by 17 of 21 cases. Exposure to fresh strawberries, mango, and to orange juice, were more common among cases but these associations were not statistically significant. The frequency of other exposures repeatedly mentioned in the trawling questionnaire ( $>70 \%$ exposure) including to different salads, jam and marmalade, ice (water-based), cooked fish, sandwiches, eggs and raw vegetables, were similar between cases and controls (data not shown). The multivariable model included exposures to strawberries, mango and orange juice: exposure to strawberries and mango remained independently significant (Table 2). Cases and controls did not significantly differ in age or sex distribution and these variables were not adjusted for in the model ( $p$ values>o.16).

\section{Vaccination status among cases and reasons for non-vaccination}

All cases interviewed with the trawling questionnaire $(n=30)$ or with only the case-control questionnaire $(n=13$ Figure 2), were included in this study. Among the 43 cases, none were vaccinated. The most common reason for not being vaccinated was not knowing that HAV vaccination was recommended, (23/43), followed by not perceiving a high risk of infection in an all-inclusive luxury resort (19/43) (Figure 3). Thirty-five of the 43 interviewed cases stayed at resorts or hotels, which were all-inclusive. Six cases sought professional medical advice before travel and for five cases vaccination was not recommended. These cases represented four different countries. When the vaccine was not recommended, a general practitioner (GP) was indicated as the specific source of advice for three of the cases, while for the two remaining, the details on source of information were missing. For the sixth case, vaccination was recommended by a GP, but this advice was eventually ignored. 
Univariate and multivariable associations between food/drink exposures and hepatitis A infection, European travellers to Egypt, November 2012-2013

\begin{tabular}{|c|c|c|c|c|c|c|}
\hline \multirow[b]{2}{*}{ Exposure item } & \multicolumn{2}{|c|}{ Exposure } & \multicolumn{2}{|c|}{ Univariate analysis } & \multicolumn{2}{|c|}{ Multivariate analysis } \\
\hline & $\begin{array}{c}\text { Cases } \mathrm{n}=27 \\
\mathrm{n} / \mathrm{N}(\%)\end{array}$ & $\begin{array}{c}\text { Controls } n=13 \\
n / N(\%)\end{array}$ & Crude OR $(95 \% \mathrm{Cl})$ & $\begin{array}{c}\text { P value } \\
\text { (Fisher exact test) }\end{array}$ & $\begin{array}{l}\text { Adjusted OR } \\
(95 \% \mathrm{Cl})\end{array}$ & $\begin{array}{c}\text { P value } \\
\text { (Wald test) }\end{array}$ \\
\hline Strawberries ${ }^{a}$ & $17 / 21(81)$ & 4/11(36) & $7.4(1.4-38.4)$ & 0.02 & $10.1(1.1-93)$ & 0.04 \\
\hline Fresh strawberries $^{b}$ & $14 / 24(58)$ & $3 / 13(23)$ & $4.6(0.9-31.9)$ & 0.08 & - & - \\
\hline Mango $^{\mathrm{a}}$ & $10 / 17(59)$ & $2 / 11(18)$ & $6.4(1.1-39.3)$ & 0.05 & $21(1.1-409)$ & 0.04 \\
\hline Fresh mango $^{b}$ & $10 / 22(45)$ & $2 / 13(15)$ & $4.5(0.7-50.1)$ & 0.14 & - & - \\
\hline Raspberries ${ }^{\mathrm{a}, \mathrm{c}}$ & $6 / 14(43)$ & $0 / 9(0)$ & $\mathrm{NA}$ & 0.05 & - & - \\
\hline Orange juice & $21 / 25(84)$ & $7 / 13(54)$ & $4.5(0.97-20.7)$ & 0.06 & $7.0(0.4-107.3)$ & 0.17 \\
\hline
\end{tabular}

$\mathrm{Cl}$ : confidence interval; OR: odds ratio; NA: not applicable.

Denominators represent persons for whom data were available for the given variable.

a As fresh fruits, in smoothies, pastries or fruit sauce.

b Fresh mango and fresh strawberries were not included in the multivariable model due to collinearity with the variables combining the different forms of fruits consumed.

Exposure to raspberries was not included in the multivariable analysis as the number of cases exposed was under 10.

\section{Discussion}

We describe a multistate outbreak of HAV sub-genotype IB infection among European travellers returning from Egypt. The outbreak highlighted the risk of hepatitis A for non-immune Europeans visiting a highly endemic country. A persistent common source of infection was suspected as identical HAV strains were isolated from several cases over a period of several weeks. Unfortunately, HAV genotyping is not routinely done in many EU countries and some laboratory-confirmed cases in the context of the outbreak may have been overlooked by the retrospective investigation. Transmission likely occurred through contaminated food, with contaminated strawberries or possibly mangos being likely vehicles of the outbreak. Cases were not aware of the vaccine recommendations or did not perceive a high risk of infection in all-inclusive holiday resorts, despite all the affected countries having explicit HAV vaccination recommendations for Egypt. Moreover, for the six cases identified among 43 interviewed in our study, which sought medical advice before travel, vaccination was not recommended for five.

The vaccine against HAV is highly immunogenic and effective [2] and the infection can be prevented when travelling to high-risk destinations by following national vaccination recommendations in nearly every European country. Our study pointed out that awareness of vaccine recommendations should clearly be improved, including among GPs giving advice on vaccinations to travellers. It is also important to reinforce that vaccination is needed in countries with high endemicity of HAV even in settings that the public consider safe, namely all-inclusive holiday resorts. A study on travelassociated HAV infections in Switzerland indicated that risk of contracting hepatitis $A$ is often underestimated in nearby regions for Europeans despite endemicity, such as northern Africa [4]. Another study showed that Swedish tourists travelling to Egypt were less frequently vaccinated than Swedish travellers to other high-risk areas, probably due to low risk perception [11], corroborating our findings.

HAV infection can lead to severe illness, particularly in older adults [1], and the direct medical costs and indirect costs of lost productivity associated with hepatitis A can be substantial [3]. Two-thirds of the cases in our study were hospitalised, showing a hospitalisation rate that is higher than usual for hepatitis A $[12,13]$. This probably reflects that only cases with a severe infection visit healthcare and are notified to the national surveillance systems. Infection in travellers may further lead to secondary transmission back in home countries, thereby further increasing the burden of travel-associated infections. Particularly, if infected travellers work in settings such as foodhandling, transmission may spread through the larger community [14]. Some secondary cases related to this outbreak were reported but we were not able to assess the full extent of secondary transmission due to our case definition restrictions in case finding.

The outbreak was most likely foodborne with transmission occurring on hotel premises, as other exposures did not concur between cases. Most cases only ate at the hotels and never left hotel grounds. Since the genetic substitution rate in HAV is considered unusually low [15] and several cases with identical HAV-strains were identified, a common source was suspected. However, multiple sources cannot be excluded and we were not able to compare full-length sequences of the HAV strains, which could have confirmed the genetic relatedness between the outbreak 


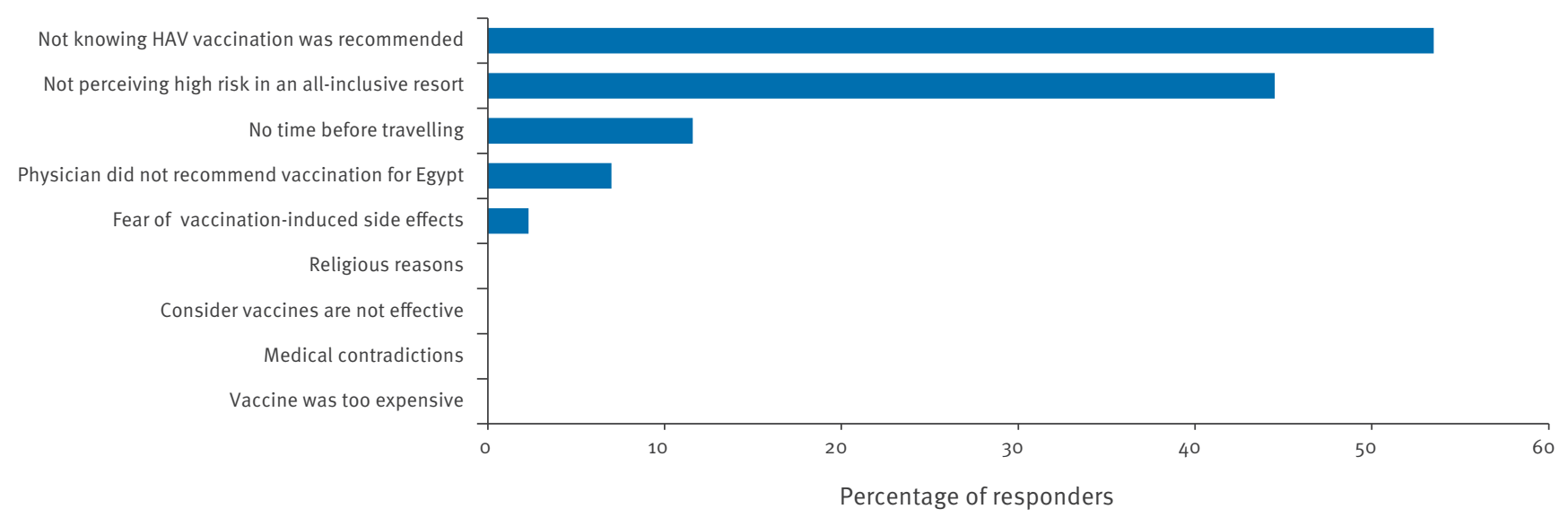

isolates. Food-borne transmission of HAV has been implicated in several outbreaks [14,16-18], including a very large hotel outbreak in Egypt in 2004 affecting travellers [19]. In that outbreak, the food vehicle also was an Egyptian produced fruit preparation (citrus juice). The recent outbreaks in Nordic countries and Italy in $\mathbf{2 0 1 3}$ were associated with the consumption of frozen strawberries and mixed berries, respectively $[20,21]$. Phylogenetic analysis indicated that the outbreak sequences from the Nordic outbreak clustered with the strain identified in this study and with other strains previously isolated from travellers returning from Egypt, suggesting these strains may have a common ancestor in Egypt or surrounding countries [20].

Our case-control study indicated that exposure to strawberries and possibly mango was associated with being infected with HAV. However, raspberries cannot be ruled out as more controls could have allowed further analyses with this exposure. Both strawberries and mango were often consumed as fresh products. Information on dose of exposure was collected but often missing and thus not analysed. The association to strawberries appears to be the most likely source of infection, given that the strawberry production season in Egypt spans from December to April, which coincides with the timing of this outbreak. In contrast, mango season is in the summer and local fresh mango thus unavailable in the winter. Strawberries are also biologically plausible, since they are ready to eat and hard to effectively wash. Contamination could have occurred upon water irrigation or rinsing near the place of production - local contamination in the various hotels seems unlikely, given the single outbreak strain. There is no evidence of a link between this outbreak and the other concurrent strawberry-associated outbreaks in Europe $[20,21]$ as the HAV strains differ. We were not able to obtain information from the hotels affected regarding menus, possibly sick food handlers, or possible distribution chains of the implicated food items, which could have explained clustering of cases in certain hotels, and enabled to further assess the findings from our analytical study.

The results from the analytical study must be interpreted with caution. The time between interviews and exposure to infection was several months and cases were possibly more likely to remember exposures than controls. Recall bias may have resulted in overestimated measures of associations. Several cases were included in both the trawling interviews and in the analytical study, which should normally be avoided but this was not feasible in our study due to restricted sample size. We were not able to retrieve lists of healthy guests from the affected hotels for control sampling. The number of controls in the case-control study was small and we could not take into account the fact that controls did not represent all the same hotels as cases. Selecting controls from travel companions may have resulted in over-matching and possibly underestimation of the strength of associations; however, this choice ensured that controls had the same chance as the cases to be exposed to the infection. Moreover, attributable to small sample size and missing data, the number of observations used in the multivariable model was rather small leading to limited power. Media attention around strawberries and HAV infection in Nordic countries (Sweden, Norway, Denmark and Finland) due to the concurrent strawberry-associated outbreak may have had an effect on recalling food exposures in our study. However, the frequency of exposure to strawberries among cases from Nordic countries was not higher than other cases in our study; in fact, it was lower (data not shown) and thus, media bias probably did not have major influence on our findings. Our study design was not specifically designed to study vaccination status and reasons for non-vaccination among travellers to Egypt in general. Therefore we were only able to study vaccination details among cases in our study and cannot generalise findings to travellers to Egypt in general. It would have been of interest to analyse reasons for non-vaccination by country of cases but this was not done due to small sample size. 
This outbreak investigation was conducted in collaboration with several public health institutes in Europe, ECDC, WHO and local Egyptian authorities. The cooperation, involving both epidemiological and microbiological investigations, was essential in an outbreak affecting several countries and occurring in a popular holiday destination and should be promoted and reinforced if similar multistate outbreaks occur in the future. However, outbreaks affecting Europeans outside EU are often challenging to investigate. For instance, the collection of important information can be cumbersome and, as also applies to outbreaks within the EU, performing environmental investigations is not always possible. Initial difficulties should not, however, discourage the investigations of events putting European travellers at risk, especially when recurrently happening in very popular destinations.

The results of our investigation suggest that public health authorities should reinforce the importance of vaccination before visiting HAV-endemic areas with information campaigns targeting travellers, travel agencies and healthcare providers, particularly the GPs often mentioned as the source of advice in this study. Hotels and travel agencies should monitor the hygiene practices in food handling and preparation more carefully and yet unvaccinated tourists should avoid food items considered likely vehicles of HAV. After previous outbreaks affecting travellers returning from Egypt, it was suggested that travel agencies should consider adding reminders of vaccination upon booking holidays to Egypt [22-24]. Recently revised proposal of an EU directive on package travel also highlights that the retailer should provide proper health information to travellers [25]. This outbreak evidently showed that more efficient actions are needed in order to improve vaccine uptake and prevent future outbreaks of HAV among travellers.

\section{Acknowledgments}

We would like to thank all employees from all the involved public health institutes across Europe who assisted in collecting epidemiological and microbiological information and conducting interviews. EPIET coordinators (Alicia Barassa, Katrine Borgen, Ioannis Karagiannis and Marion Muehlen) are also thanked for their assistance in the writing of the manuscript. Assistance from Egyptian Public Health Authorities and WHO EURO and EMRO is also appreciated.

\section{Conflict of interest}

None declared.

\section{Authors' contributions}

JS designed the study, coordinated the data collection, analysed the data and wrote the manuscript, EM contributed to the study design, collected data and wrote the manuscript, LV contributed to the study design, supervised the study in Norway and wrote the manuscript, CG contributed to study design, coordinated data collection and wrote the manuscript, ES designed the study, analysed data, coordinated data collection and wrote the manuscript. Members of the International Outbreak Team contributed with data from respective countries and reviewed the study design and manuscript.

Members of the International Outbreak Investigation Team

European Center for Disease Control (ECDC): Jaime Martinez Urtaza Joana Gomes Dias Josep Jansa Denmark (Statens Serum Institut) Julita Gil (EPIET) Sofie Elisabeth Midgley Sofie Gillesberg Lassen Estonia (Health Board) Natalja Võželevskaja Finland (National Institute for Health and Welfare) Pieter Smit (EUPHEM) Ruska Rimhanen-Finne France Anne-Marie Roque-Afonso (National Reference Center for hepatitis A virus) Elisabeth Couturier (Institut de Veille Sanitaire) Germany (Robert Koch Institute) Max Gertler (EPIET) Mirko Faber Christina Frank Ireland Joanne O'Gorman (National Virus Reference Laboratory) Lelia Thornton (Health Protection Surveillance Centre) Latvia (Centre for Disease Prevention and Control of Latvia) Rita Korotinska Lithuania Rasa Liausediene Netherlands (National Institute for Public Health and the Environment) Harry Vennema Linda Verhoef Marion Koopmans Norway (Norwegian Institute of Public Health) Anneke Steens (EPIET) Kathrine SteneJohansen Slovakia Ján Mikas Katarína Krajcírová Sweden Michael Edelstein (EPIET) UK (Public Health England) Joanne Freedman Jonathan Crofts Koye Balogun Siew Lin Ngui.

\section{References}

1. Jacobsen K. The global prevalence of hepatitis A virus infection and susceptibility: a systematic review. World Health Organization: Geneva; 2009.

2. WHO position paper on hepatitis A vaccines: June 2012-recommendations. Vaccine. 2013;31(2):285-6. http:// dx.doi.org/10.1016/j.vaccine.2012.10.102 PMID:23142134

3. Jacobsen $\mathrm{KH}$, Wiersma ST. Hepatitis A virus seroprevalence by age and world region, 1990 and 2005 . Vaccine. 2010;28(41):6653-7. http://dx.doi.org/10.1016/j. vaccine.2010.08.037 PMID:20723630

4. Mutsch M, Spicher VM, Gut C, Steffen R. Hepatitis A virus infections in travelers, 1988-2004. Clin Infect Dis. 2006;42(4):490-7. http://dx.doi.org/10.1086/499816 PMID:16421793

5. Nothdurft HD, Dahlgren AL, Gallagher EA, Kollaritsch H, Overbosch D, Rummukainen ML, et al.; ad hoc Travel Medicine Expert Panel for ESENEM. The risk of acquiring hepatitis $A$ and $B$ among travelers in selected Eastern and Southern Europe and non-European Mediterranean countries: review and consensus statement on hepatitis $A$ and $B$ vaccination. Travel Med. 2007;14(3):181-7. http://dx.doi.org/10.1111/j.1708 8305.2007.00123.x PMID:17437475

6. Demicheli V, Tiberti D. The effectiveness and safety of hepatitis A vaccine: a systematic review. Vaccine. 2003;21(1920):2242-5. http://dx.doi.org/10.1016/S0264-410X(03)00135-X PMID:12744850

7. MacDonald E, Steens A, Stene-Johansen K, Gillesberg Lassen $\mathrm{S}$, Midgley S, Lawrence J, et al. Increase in hepatitis A in tourists from Denmark, England, Germany, the Netherlands, Norway and Sweden returning from Egypt, November 2012 to March 2013. Euro Surveill. 2013;18(17):20468. PMID:23647624

8. Kamel AH, Ali MA, El-Nady HG, Deraz A, Aho S, Pothier P, et al. Presence of enteric hepatitis viruses in the sewage and population of Greater Cairo. Clin Microbiol Infect. 2011;17(8):1182-5. http://dx.doi.org/10.1111/j.14690691.2011.03461.x PMID:21375654

9. European Centre for Disease Prevention and Control (ECDC). Rapid Risk Assessment. Outbreak of hepatitis A virus infection in travellers returning from Egypt. Stockholm: ECDC; 2013.

10. Vittinghoff $E, M c C u l l o c h ~ C E$. Relaxing the rule of ten events per variable in logistic and Cox regression. Am J Epidemiol. 2007;165(6):710-8. http://dx.doi.org/10.1093/aje/kwk052 PMID:17182981

11. Askling HH, Rombo L, Andersson Y, Martin S, Ekdahl K. Hepatitis A risk in travelers. J Travel Med. 2009;16(4):2338. http://dx.doi.org/10.1111/j.1708-8305.2009.00307.x PMID:19674261 
12. Arteaga A, Carrasco-Garrido P, de Andres AL, de Miguel AG, Jiménez-García R. Trends of hepatitis A hospitalizations and costs associated with the hospitalization in Spain (2000-2005). J Viral Hepat. 2009;16(4):286-91. http://dx.doi.org/10.1111/ j.1365-2893.2009.01075.x PMID:19200130

13. Faber MS, Stark K, Behnke SC, Schreier E, Frank C. Epidemiology of hepatitis A virus infections, Germany, 20072008. Emerg Infect Dis. 2009;15(11):1760-8. http://dx.doi. org/10.3201/eid1511.090214 PMID:19891863

14. Robesyn E, De Schrijver K, Wollants E, Top G, Verbeeck J, Van Ranst $M$. An outbreak of hepatitis $A$ associated with the consumption of raw beef. J Clin Virol. 2009;44(3):207-10. http://dx.doi.org/10.1016/j.jcv.2008.12.012 PMID:19179106

15. Cristina J, Costa-Mattioli M. Genetic variability and molecular evolution of hepatitis A virus. Virus Res. 2007;127(2):1517. http://dx.doi.org/10.1016/j.virusres.2007.01.005 PMID:17328982

16. Donnan EJ, Fielding JE, Gregory JE, Lalor K, Rowe S, Goldsmith $P$, et al. A multistate outbreak of hepatitis A associated with semidried tomatoes in Australia, 2009. Clin Infect Dis. 2012;54(6):775-81. http://dx.doi.org/10.1093/cid/cir949 PMID:22238166

17. Gallot C, Grout L, Roque-Afonso AM, Couturier E, CarrilloSantisteve P, Pouey J, et al. Hepatitis A associated with semidried tomatoes, France, 2010. Emerg Infect Dis. 2011;17(3):566-7. http://dx.doi.org/10.3201/eid1703.101479 PMID:21392466

18. Hutin YJ, Pool V, Cramer EH, Nainan OV, Weth J, Williams IT, et al.; National Hepatitis A Investigation Team. A multistate, foodborne outbreak of hepatitis A. N Engl Med. 1999;340(8):595-602. http://dx.doi.org/10.1056/ NEJM199902253400802 PMID:10029643

19. Frank C, Walter J, Muehlen M, Jansen A, van Treeck U, Hauri AM, et al. Major outbreak of hepatitis A associated with orange juice among tourists, Egypt, 2004. Emerg Infect Dis. 2007;13(1):156-8. http://dx.doi.org/10.3201/eid1301.060487 PMID:17370535

20. Nordic Outbreak Investigation Team C. Joint analysis by the Nordic countries of a hepatitis A outbreak, October 2012 to June 2013: frozen strawberries suspected. Euro Surveill. 2013;18(27):20520. PMID: 23870076

21. Rizzo C, Alfonsi V, Bruni R, Busani L, Ciccaglione A, De Medici D, et al.; Central Task Force on Hepatitis A. Ongoing outbreak of hepatitis A in Italy: preliminary report as of 31 May 2013. Euro Surveill. 2013;18(27):20518. http://dx.doi. org/10.2807/1560-7917.ES2013.18.27.20518 PMID:23870075

22. Bernard H, Frank C. Cluster of hepatitis A cases among travellers returning from Egypt, Germany, September through November 2008. Euro Surveill. 2009;14(3). PMID:19161724

23. Robesyn E, Micalessi MI, Quoilin S, Naranjo M, Thomas I. Cluster of hepatitis A cases among travellers returning from Egypt, Belgium, September through November 2008. Euro Surveill. 2009;14(3):19096. PMID:19161725

24. Ward M, Borgen K, Mazick A, Muehlen M. Hepatitis A vaccination policy for travellers to Egypt in eight European countries, 2004. Euro Surveill. 2006;11(1):37-9. PMID:16484731

25. European Commission. Proposal for a directive of the European Parliament and of the Council on package travel and assisted travel arrangements. Brussels: European Commission; 2013. Available from: http://ec.europa.eu/justice/ consumer-marketing/files/com_2013_512_en.pdf 